\title{
The Effects of Geography on Outcomes of Routine Early Versus Selective Late Revascularization Strategy in the Treatment of Unstable Angina and Non-ST-Segment Elevation Myocardial Infarction: A Meta-Analysis of Transatlantic Randomized Controlled Trials
}

\author{
Hafeez U1 Hassan Virk ${ }^{\mathrm{a}, \mathrm{d}}$, Kevin Bryan Lo ${ }^{\mathrm{a}}$, Chayakrit Krittanawong ${ }^{\mathrm{b}}$, Faisal Inayat ${ }^{\mathrm{a}}$, \\ Usman Sarwarc ${ }^{c}$, Ali Raza Ghanic, Christian Witzke ${ }^{\mathrm{a}}$, Sean Janzer ${ }^{\mathrm{a}}$, Jon C. George ${ }^{\mathrm{a}}$, \\ Gregg Pressman a, Behnam Bozorgnia ${ }^{\mathrm{a}}$, Saurav Chatterjee ${ }^{\mathrm{c}}$, \\ Vincent M. Figueredo ${ }^{\mathrm{a}}$
}

\begin{abstract}
Background: The optimal timing of revascularization in unstable angina (UA) or non-ST-segment elevation myocardial infarction (NSTEMI) remains uncertain. We compared routine early revascularization (REV) versus selective late revascularization (SLR) strategies and divergence in the approach of cardiologists in the United States and Europe.
\end{abstract}

Methods: Seventeen randomized controlled trials (RCTs) $(15,812$ patients) were extracted from PubMed, Cochrane Library, EMBASE and Web of Science databases. The data were pooled using the Der Simonian and Laird random-effect models and expressed as pooled risk ratios (RR) with $95 \%$ confidence intervals (95\% CIs).

Results: Overall, there was no difference in all-cause mortality (RR: 1.01, 95\% CI: $0.95-1.08, \mathrm{P}=0.7)$, myocardial infarction $(\mathrm{MI})(\mathrm{RR}$ : $0.98,95 \% \mathrm{CI}: 0.79-1.22, \mathrm{P}=0.85)$ or coronary artery bypass grafting $(\mathrm{CABG})(\mathrm{RR}: 1.33,95 \% \mathrm{CI}: 0.92-1.91, \mathrm{P}=0.12$ ) between REV and SLR strategy. There were trends of decreased incidence of MI in REV, $13.3 \%(1,029 / 7,704)$ vs. $15.1 \%(1,108 / 7,314)$ in SLR $(P=$ $0.007)$, and rate of CABG was higher in REV, $4.9 \%(140 / 2,831)$ vs. $3.7 \%(105 / 2,819)$ in SLR $(\mathrm{P}=0.031)$. There were trends of lower allcause mortality in the combined US/international trials in both REV $8.4 \%(390 / 4,624)$ vs. $22.8 \%(908 / 3,975)(\mathrm{P}<0.001)$ and SLR $8 \%$ $(359 / 4,421)$ vs. $24 \%(910 / 3,808)(\mathrm{P}<0.001)$ compared to the Euro-

Manuscript submitted September 14, 2018, accepted October 22, 2018

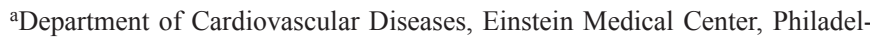
phia, PA, USA

bDepartment of Cardiology, Mount Sinai St Luke's Hospital, New York, NY, USA

'Department of Medicine, Abington-Jefferson Health, Abington, PA, USA

${ }^{\mathrm{d} C o r r e s p o n d i n g ~ A u t h o r: ~ H a f e e z ~ U 1 ~ H a s s a n ~ V i r k, ~ D e p a r t m e n t ~ o f ~ C a r d i o v a s c u-~}$ lar Diseases, Einstein Medical Center, Philadelphia, PA, USA.

Email: hafeezvirkmd@gmail.com

doi: https://doi.org/10.14740/jocmr3585w pean trials. There were also trends of lower rates of MI in the European trials in the REV group $20 \%(623 / 3,080)$ vs. $25 \%(712 / 2,893)$ in SLR $(P=0.001)$ and higher rates of CABG in REV 8.3\% $(96 / 1,144)$ vs. $5.7 \%(67 / 1,165)$ in SLR $(P=0.02)$; however, there were no significant effects in the pooled RR ratios even after subgroup analysis between US/international trials and European trials.

Conclusions: Despite having contemporary differences in the management approach towards UA/NSTEMI patients, no significant differences in trends were observed with REV strategy in US/international trials vs. European trials.

Keywords: Unstable angina; Non-ST-segment elevation myocardial infarction; Routine early revascularization; Selective late revascularization

\section{Introduction}

Routine early revascularization (REV)/early invasive strategy versus selective late revascularization (SLR)/ischemia-guided strategy are generally used to manage patients with unstable angina (UA) and non-ST-segment elevation myocardial infarction (NSTEMI) [1,2]. However, superiority of either approach is still under debate with numerous studies and meta-analyses published over the last decade with different outcomes, limitations and clinical implications. Even the guidelines differ in their recommendations, with the European guidelines leaning towards REV and the AHA/ACC guidelines inclining towards both REV and SLR based on the appropriate patient population $[1,2]$. So far, the most recent Cochrane meta-analysis published in 2016 showed appreciable risk reduction in refractory angina, myocardial infarction (MI) and re-hospitalization but no difference in all-cause mortality and death or nonfatal MI at 6 - 12 months with REV therapy [3]. However, over the past 2 years, results of long-term (10 - 15 year) follow-up of 
trials evaluating REV vs. SLR strategies have been published shedding light on potentially valuable long-term clinical outcomes. A close look and analysis of these trials together with previous results are particularly warranted. In addition, majority of these trials comparing these two strategies have been done either in Europe or the US/multicenter international trials. To date, no specific analysis has been done as to the effect of geographical location together with its implied differences in guideline-directed management.

\section{Methods}

\section{Search strategy}

We conducted a comprehensive search of five databases with human studies in any language from inception to June 2018. The databases included Ovid Medline In-Process \& Other Non-Indexed Citations, Ovid MEDLINE, Ovid Embase, Ovid Cochrane Central Register of Controlled Trials, and Scopus. No language restriction was imposed, and only human studies were considered. The search strategy was designed and conducted by investigators. Controlled vocabulary, supplemented with keywords, was used to search for relevant studies. Search terms used were: "invasive strategy", "routine invasive strategy", "selective invasive strategy", "non-ST-segment elevation myocardial infarction", "unstable angina" and "acute coronary syndrome".

\section{Study selection}

Studies were included in this meta-analysis if they satisfied the following criteria: 1) The study design was prospective, randomized controlled trials (RCTs) comparing REV versus SLR strategy for UA/NSTEMI; 2) Studies providing desired outcomes, particularly revascularization, death and bleeding. We excluded reviews, editorials, non-human studies and studies without sufficient data. In addition, we excluded studies which included patients with NSTEMI, but not with desired outcomes. Studies of ST-segment elevation myocardial infarction and stable angina were also excluded.

\section{Data extraction}

Two authors (H.V. and C.K.) independently carried out data extraction using a standard extraction form. We extracted the following information from each study: authors, year of publication, study name, study location, years of follow-up, sample size (number of participants and incident cases), diagnostic criteria, participants' characteristics (age, gender and body mass index), length of follow-up, cardiovascular mortality, allcause mortality, revascularization, and bleeding.

\section{Quality assessment}

Two authors (C.K. and H.V.) independently assessed the risk of bias for each study by using the modified Newcastle-Ottawa Scale (NOS). We resolved disagreements by discussion or by involving the co-authors to adjudicate and establish consensus. The quality of studies was no longer individually numerically quantified as all studies included were randomized controlled trials.

\section{Statistical analysis}

We extracted or calculated relative risks (RR) and 95\% confidence intervals (CI) from the included studies. For studies reporting odds ratios (ORs) or hazard ratios (HRs), as cardiovascular events were rare $(<1 \%)$, HRs and ORs asymptotically approach RRs, and they were treated as RRs in the analysis. We converted RR to $\log$ transformed RR ( $\log R R)$ and pooled the $\log \mathrm{OR}$ from all the included studies using the DerSimonian and Laird random-effects method with the estimate of heterogeneity from the Mantel-Haenszel model. Exploratory random-effect meta-regression analyses were conducted to assess the influence of study characteristics (geographical location and type of study design) on study results. We also conducted subgroup analyses stratified according to the geographic location (region and country). The performances of subgroup-specific and statistical test of interactions among subgroups were assessed. Heterogeneity between the studies was evaluated using $\mathrm{I}^{2}$, in which $>50 \%$ suggests substantial heterogeneity. Due to a limited number of studies included in each analysis and/ or substantial heterogeneity, we could not evaluate potential publication bias. All statistical analyses were performed with Review Manager (RevMan) (computer program) (Version 5.3. Copenhagen: The Nordic Cochrane Centre, The Cochrane Collaboration, 2014), and test of proportions was performed using SPSS by IBM Build 1.0.0.903. All tests were two-sided with a significance level of 0.05 . The meta-analysis has been reported in accordance with the Meta-analysis of Observational Studies in Epidemiology guidelines (MOOSE).

\section{Results}

Seventeen trials were included with a total of 15,812 patients. Out of 11 trials (7,783 patients) which were conducted in Europe, 3,975 patients were randomized to REV strategy and 3,808 patients were randomized to SLR strategy. Out of six trials $(8,029$ patients) which were conducted in the US/multicenter international trials, 4,112 patients were randomized into REV and 3,917 patients were randomized into SLR strategy. Average age of the patients included was 64.7 years (66 years in European and 61 years in US/international trials); $68 \%$ of patients were male. Average follow-up period of European and US/international trials was 43 months and 18.4 months, respectively. Baseline characteristics of European and the US/ international trials are mentioned in Table 1 [4-20]. Similarly, outcome characteristics of European and US/international trials are summarized in Table 2 [4-20].

Overall, there was no difference in all-cause mortality (RR: 1.01, 95\% CI: 0.95 - 1.08, P=0.7), MI (RR: 0.98, 95\% 
Table 1. Baseline Characteristics of European and North American Trials [4-20]

\begin{tabular}{|c|c|c|c|c|c|c|c|c|}
\hline & Authors & $\begin{array}{l}\text { Follow- } \\
\text { up }\end{array}$ & $\begin{array}{l}\text { Patients } \\
\text { in REV } \\
\text { group }\end{array}$ & $\begin{array}{l}\text { Patients } \\
\text { in SLR } \\
\text { group }\end{array}$ & $\begin{array}{l}\text { Age } \\
\text { (yrs) }\end{array}$ & $\begin{array}{l}\text { Male } \\
(\%)\end{array}$ & $\begin{array}{l}\text { Diabetes } \\
\text { mellitus } \\
(\%)\end{array}$ & $\begin{array}{l}\text { Hyperten- } \\
\text { sion }(\%)\end{array}$ \\
\hline \multicolumn{9}{|l|}{ European trials } \\
\hline FRISC-II [4] & Wallentin et al (2016) & 15 years & 1,222 & 1,235 & 66 & 72 & 13 & 30 \\
\hline RITA-3 [5] & Hernderson et al (2015) & 10.6 years & 895 & 915 & 63 & 61 & 15 & 35 \\
\hline ITALIAN ELDERLY ACS [15] & Savonitti et al (2012) & 12 months & 154 & 159 & 81.8 & 49 & 38 & 92 \\
\hline ISAR COOL [16] & Neumann et al (2003) & 1 month & 203 & 207 & 70 & 66 & 26.1 & 85.5 \\
\hline LIPSIA NSTEMI [11] & Thiele et al (2011) & 6 months & 400 & 200 & 69 & 68 & 41 & 82 \\
\hline OPTIMA [19] & Riezebos et al (2009) & 6 months & 73 & 69 & 63 & 51 & 19 & 53 \\
\hline TRUCS [10] & Michalis et al (2000) & 12 months & 76 & 72 & 62 & 76 & 29 & 54 \\
\hline VINO [20] & Spacek et al (2002) & 6 months & 64 & 67 & 65.7 & 50 & 30 & 60 \\
\hline \multicolumn{9}{|l|}{ North American trials } \\
\hline MATE [7] & McCullough et al (1998) & 21 months & 111 & 90 & 57 & 77 & 11 & - \\
\hline OASIS 5 [9] & Swahn et al (2009) & 24 months & 92 & 92 & 68.2 & 74 & 14 & 62 \\
\hline TACTUS TIMI 18 [17] & Cannon et al (2001) & 6 months & 1,114 & 1,106 & 60 & 65 & 28 & - \\
\hline TIMACS [14] & Mehta et al (2009) & 6 months & 1,593 & 1,438 & 65 & 63.2 & 26.5 & - \\
\hline TIMI IIIB [18] & Anderson et al (1995) & 12 months & 740 & 733 & - & 66 & - & - \\
\hline VANQUISH [8] & Boden et al (1998) & 23 months & 462 & 458 & 62 & 97 & 24.9 & 56.7 \\
\hline
\end{tabular}

REV: routine early revascularization; SLR: selective late revascularization.

CI: $0.79-1.22, \mathrm{P}=0.85)$ or coronary artery bypass grafting (CABG) (RR: 1.33, 95\% CI: $0.92-1.91, \mathrm{P}=0.12$ ) between REV and SLR strategy (Figs. 1-3). There was however trend towards decreased incidence of MI in REV, 13.3\% (1,029/7,704) vs. $15.1 \%(1,108 / 7,314)$ in SLR $(P=0.007)$ based on test of proportions analysis. In contrast, rate of $\mathrm{CABG}$ was higher in $\mathrm{REV}, 4.9 \%(140 / 2,831)$ vs. $3.7 \%(105 / 2,819)$ in SLR $(\mathrm{P}=$ $0.031)$. All of these trends however did not translate into significant effects based on the pooled risk ratios in the results of the meta-analysis (Figs. 2, 3).

In the US/international trials, incidence of all-cause mortality is much lower in REV $8.4 \%(390 / 4,624)$ vs. $22.8 \%$ $(908 / 3,975)(\mathrm{P}<0.001)$ in European trials (Fig. 1); and in SLR $8 \%(359 / 4,421)$ vs. $24 \%(910 / 3,808)(\mathrm{P}<0.001)$ based on the test of proportions analysis. However, this did not translate into significant changes in effects based on the pooled RR ratios in the meta-analysis even after subgroup analysis between US/ international and European trials $(\mathrm{P}=0.59$, Fig. 1$)$. In the US/ international trials, incidence of $\mathrm{MI}$ in either group was similar: 8.7\% $(406 / 4,624)$ in REV vs. 8.9\% $(396 / 4,421)$ in SLR (P $=0.8)$, whereas in European trials, REV had lower incidence of MI, $20 \%(623 / 3,080)$ vs. $25 \%(712 / 2,893)(\mathrm{P}=0.001)$, but no significant differences in the pooled RR ratios after subgroup analysis between US/international and European trials ( $\mathrm{P}=0.53$, Fig. 2). In US/international trials, rate of CABG was comparable between both groups, $2.7 \%(44 / 1,607)$ in REV and $2.3 \%(38 / 1,654)$ in SLR $(\mathrm{P}=0.44)$, whereas in European trials, rate of CABG was higher in REV, 8.3\% $(96 / 1,144)$ vs. $5.7 \%$ $(67 / 1,165)(\mathrm{P}=0.02)$, however, no significant differences in the pooled RR ratios after subgroup analysis between US/international and European trials $(\mathrm{P}=0.42$, Fig. 3$)$.

\section{Discussion}

We report an up-to-date meta-analysis comparing REV vs. SLR strategies opted for the treatment of UA/NSTEMI across the Atlantic. First, there was no difference in all-cause mortality rate of CABG and MI between REV and SLR strategies. Second, there was a trend of decreased incidence of MI and increased rates of CABG in the REV group, driven mostly by analogous trends in European trials. Third, in US/international trials, all-cause mortality was lower in REV group as compared to SLR group. These findings are consistent with a previous Cochrane analysis published in 2016 [3]. However, this prior analysis did not include the new long-term data from the FRISC-II [4], RITA-3 [5] and ICTUS [6] trials, which have been published recently.

In US/international trials, incidence of all-cause mortality in the REV group was lower than that in the European trials ( $8.4 \%$ vs. $22.8 \%)$, whereas incidence of $\mathrm{MI}$ and rates of CABG were similar in REV and SLR groups in the US/international trials. A potential explanation is that the US/international trials generally had shorter follow-up of about 1 year except for 


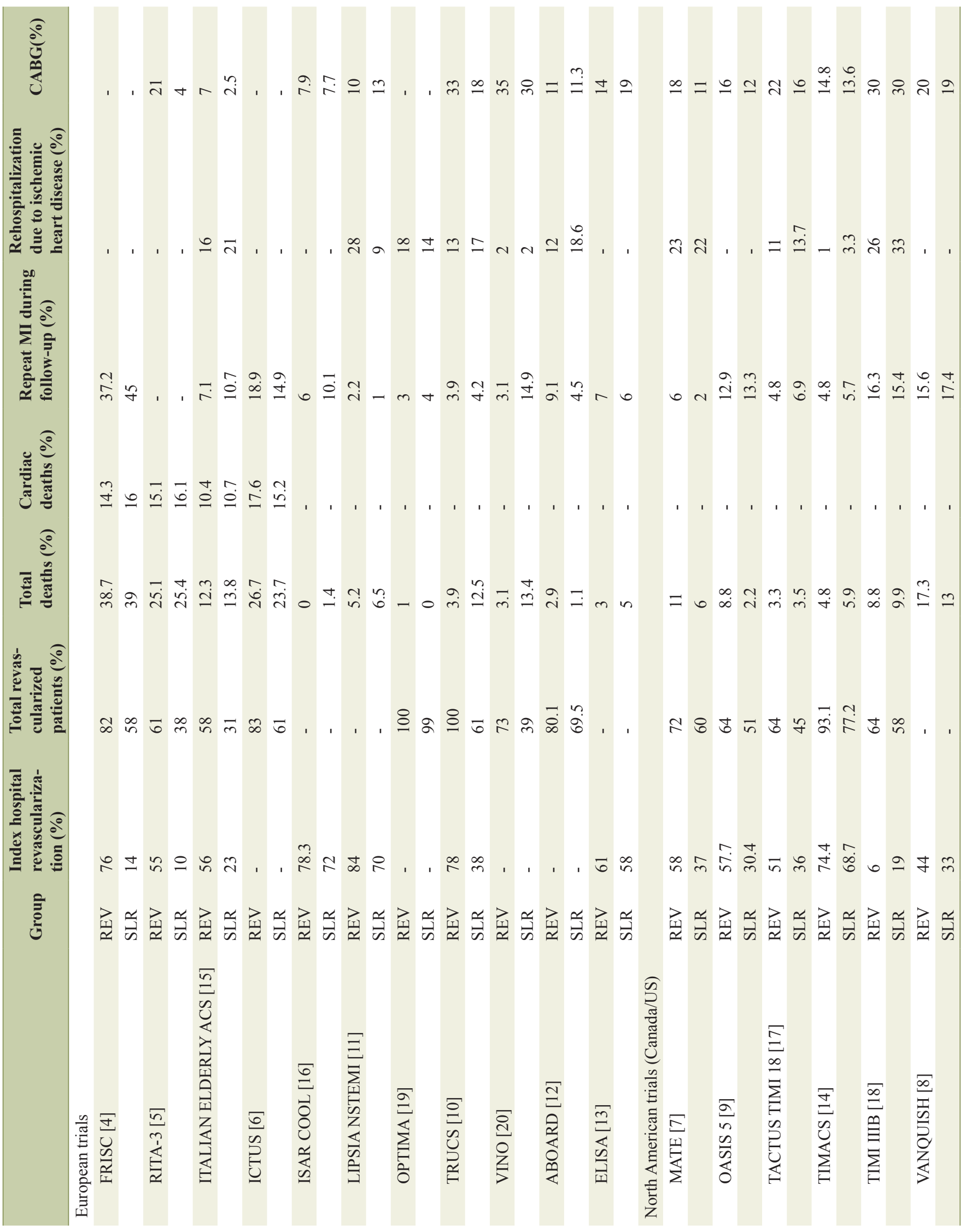




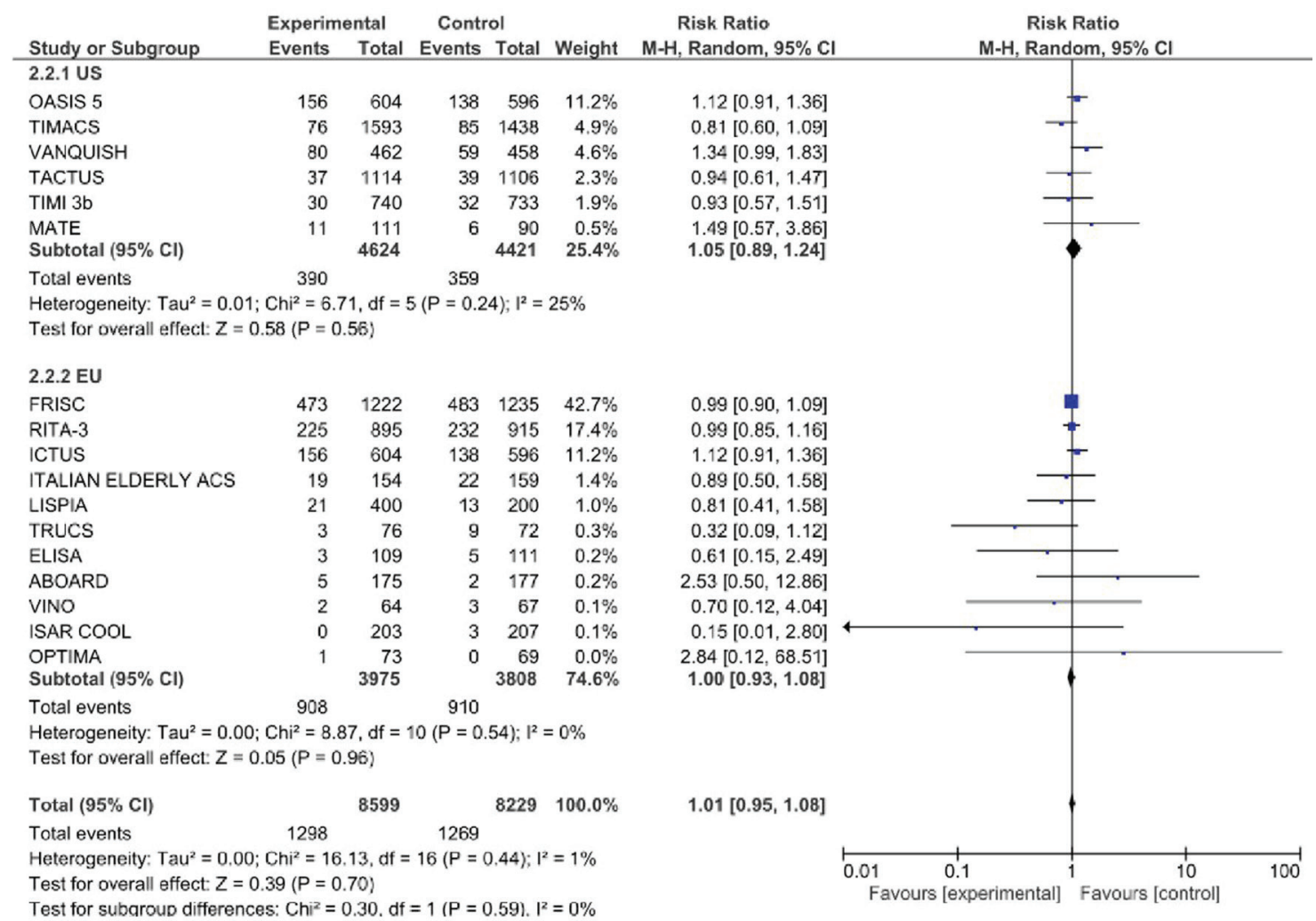

Figure 1. Rate of all-cause mortality in routine early revascularization (REV) versus selective late revascularization (SLR) in randomized controlled trials conducted in Europe and the United States. Boxes represent the weight/effect size for each study; the diamonds reflect the pooled combined effect from the meta-analysis.

the MATE [7], VANQWISH [8] and OASIS-5 [9] trials which were up to 20 months, while the European trials had 10 to 15 years follow-up, garnering more mortality data. REV strategy had a trend of lower incidence of MI in European trials, in contrast to US/international trials where an increased incidence of MI was observed. An explanation for this was the significant heterogeneity in the US/international studies in terms of MI with the MATE trial skewing the results as it included subjects with ST-elevation MI in the analysis [7], and we were unable to extract or differentiate the date pertaining to only NSTEMI patients for this study, thus another explanation for the heterogeneity. In US/international trials, rate of CABG was comparable between both groups, whereas in European trials, rate of CABG was higher in the REV group. However, there was significant heterogeneity as the results are being skewed by the TRUCS study [10] wherein the investigators intentionally randomized patients to onsite balloon angioplasty plus emergency airlift for bypass surgery versus conservative medical treatment; thus, the higher rates of CABG. After exclusion of all these studies which skew the data, the likelihood of difference is small.

In looking for geographical differences in outcomes in REV versus SLR, we had to look at potential studies conducted in the US/international and Europe, including some old studies done before 2000, as some of them had the latest long-term follow-up data available for further analysis. However, the pitfall to this is that these studies may no longer be representative of contemporary standards of medical practice as a lot of progress has happened over the past 10 years. Some of the data derived is also limited by the natural differences in methodology such as the duration of follow-up, with most studies with 1 year or less follow-up duration, but several studies with 10 years or longer follow-up. As of now there is a mounting need to conduct more studies, this time incorporating most of the advances in guideline directed medical therapy including statins, newer antiplatelet agents as well as the highly sensitive troponin assays [21] and other new biomarkers. This is to help classify patients at a higher risk for which the evidence for benefit for REV was the highest based on the previous studies [22, 23]. In a different light, as some of the studies like the ICTUS [6] and LIPSIA-NSTEMI [11] trials involving only patients with positive troponin levels labeling them as higher risk showed no difference between REV and SLR strategies, therefore a better method of risk factor assessment and risk stratification which includes other variables is needed. There is a possibility that the previous trials did not fully capture the higher risk groups hence the ambiguous results; as recorded mortality rates have been lower compared to the large multinational registry GRACE cohort with mortality rates approaching about $12 \%$ at 6 months after discharge [24]. Another important limitation in interpretation is the differences in the timing of the invasive procedures. The ABOARD [12], ELISA [13] and TIMACS [14] trials tend- 


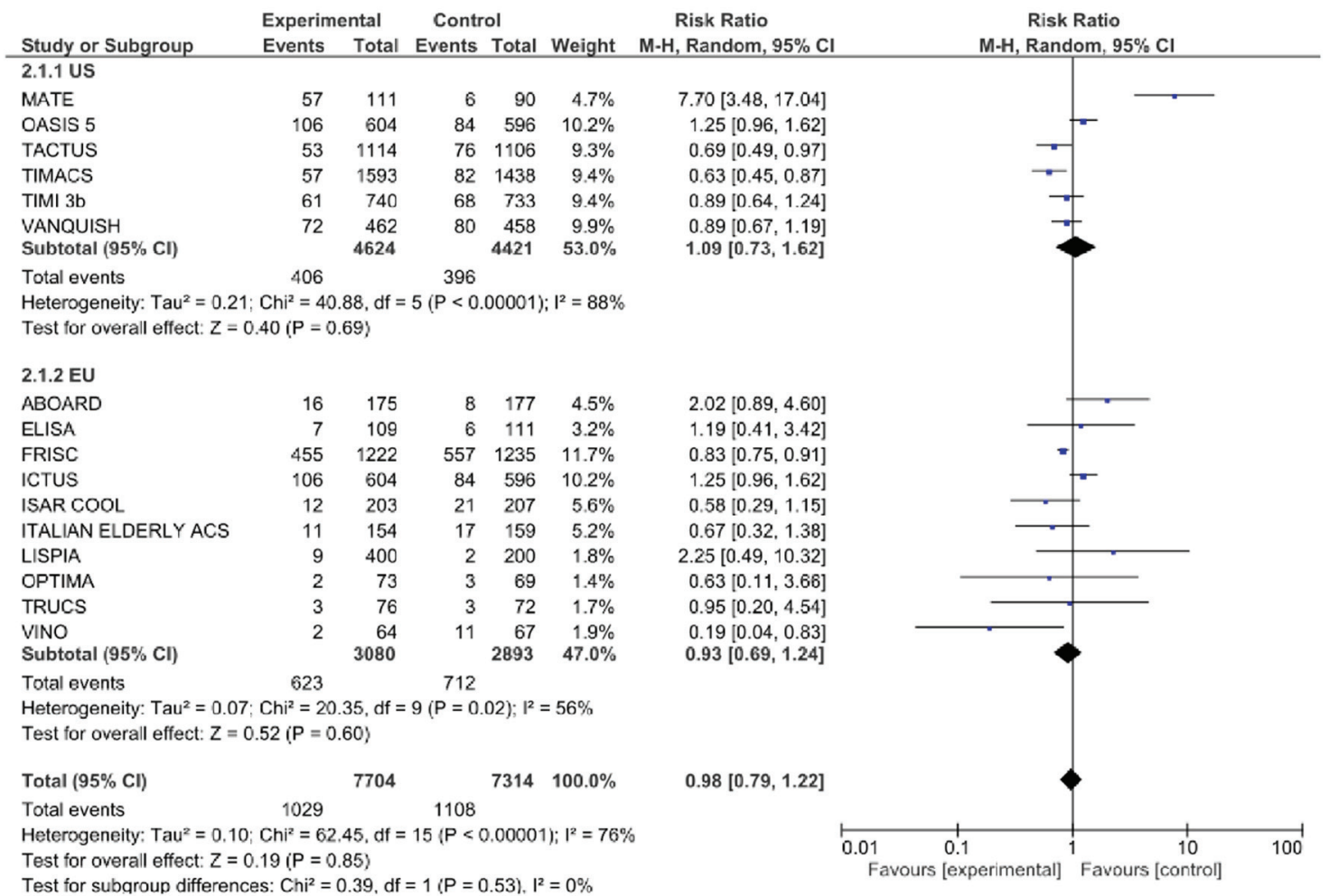

Figure 2. Rate of myocardial infarction (MI) after index hospitalization in routine early revascularization (REV) versus selective late revascularization (SLR) in randomized controlled trials conducted in Europe and the United States. Boxes represent the weight/effect size for each study; the diamonds reflect the pooled combined effect from the meta-analysis.

ed to employ the invasive strategy earlier from as early as 70 min for the ABOARD trial to less than $24 \mathrm{~h}$ in the ELISA [13] and TIMACS [14] trials, while the delayed invasive group got it within 48 - $72 \mathrm{~h}$. In comparison, in the old trials ICTUS

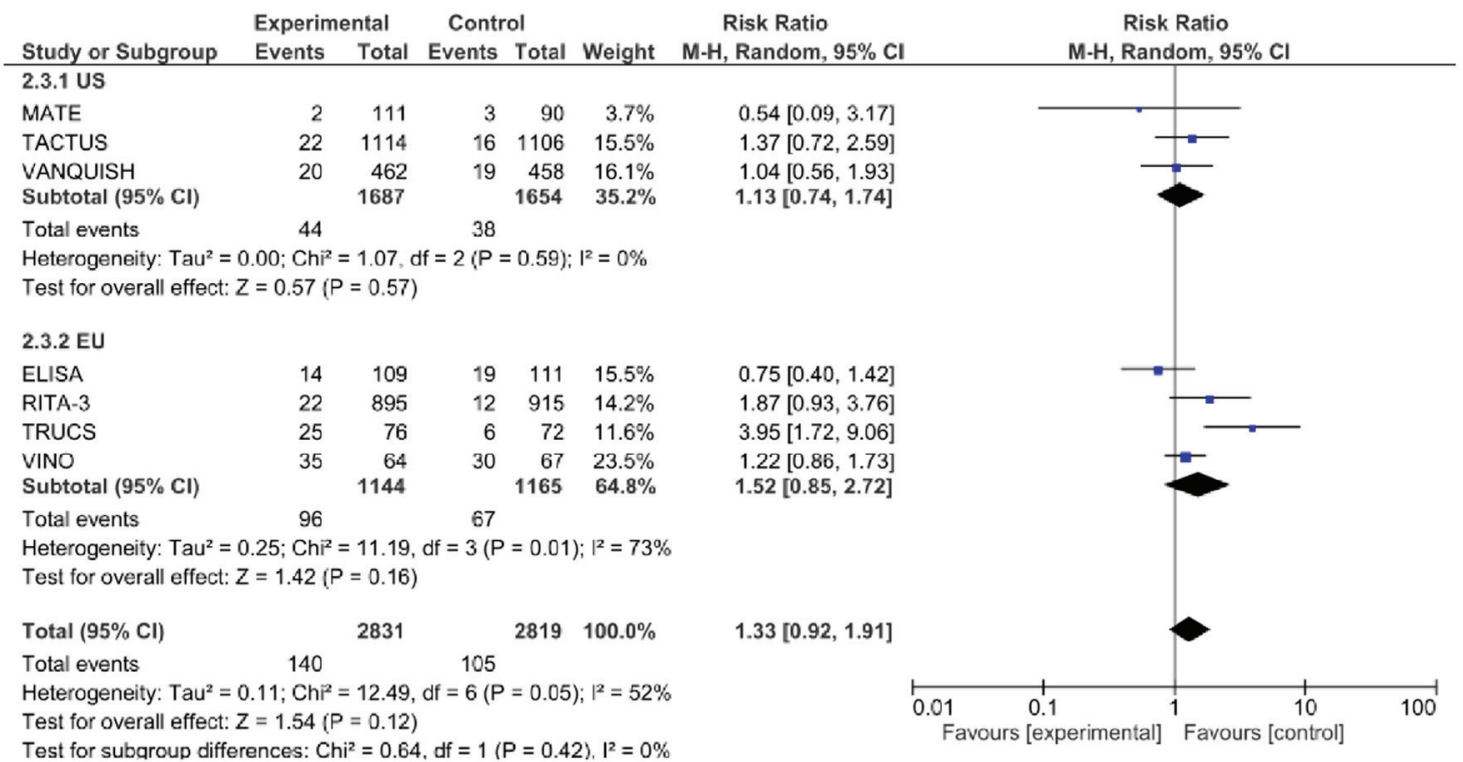

Figure 3. Rate of coronary artery bypass grafting $(C A B G)$ in routine early revascularization (REV) versus selective late revascularization (SLR) in randomized controlled trials conducted in Europe and the United States. Boxes represent the weight/effect size for each study; the diamonds reflect the pooled combined effect from the meta-analysis. 
[6], FRISC-II [4] and RITA-3 [5], SLR group got angiography only after certain criteria were met, such as recurrent symptoms or positive stress test. This can potentially alter results as meta-analyses have shown that an early invasive approach (within $24 \mathrm{~h}$ ) resulted in reduced hospital stays, and reduced rates of bleeding, death, MI or stroke [25].

The rate of CABG was higher in the REV group. Studies that recruited their cohorts early such as RITA-3 [5] and FRISC II [4] had higher rates of CABG while lower rates were found in the newer studies such as LIPSIA-NSTEMI [11] and the Italian Elderly ACS study [15]. This is consistent with improving techniques/change in guidelines with increased use of high-risk and left main stenting in recent years. Another reason for the lower rate of CABG in the Italian Heart Study is also inclusion of a more elderly cohort (mean age: 81.8 years) which makes them less likely to be candidates for CABG.

It is also noted that there is a general trend of diminishing returns for benefits of the REV strategy. With the first metaanalysis done in 2006 with a mean follow-up of about 2 years, lower rates of all-cause mortality, non-fatal MI and rehospitalization for angina were noted with REV strategy [26]. This effect was still apparent but somewhat diminished with analysis of studies with subsequent 5-year follow-up, namely FRICS-II [4], RITA-3 [5] and ICTUS [6]. The only outcome significant in these studies was a composite of cardiovascular death and non-fatal MI with some trends towards less cardiovascular deaths and all-cause deaths [27]. Recently, the long-term outcomes of both the RITA-3 [5] trial and the ICTUS [6] trial have been published, both of which have a 10-year follow-up period. There was no benefit in all-cause mortality and cardiovascular mortality among patients who underwent the REV [5, $6]$. In contrast, the FRISC-II trial analyzed the data differently. Although the difference in mortality was not sustained during the 15-year follow-up, they found that the REV delayed the occurrence of death or next myocardial infarction by as much as 18 months; the difference mainly driven by the postponement of new MI [4]. Some arguments for this difference in outcomes might be attributed to the fact that FRISC-II had the largest patient population, biggest difference in revascularization rates between groups and least crossover between both groups [4]. However, the role of diminishing returns of the REV strategy over the long term is still glaringly obvious. A possible explanation for this is that both the RITA-3 and FRISC-II studies recruited their patient population early, in an era where drug-eluting stent was used, and dual platelet antagonists were still not the norm [28]. The ICTUS trial recruited patients later from 2001 - 2003 but had a lot of crossover between REV and SLR groups which might have diminished the long-term benefit of REV [6]. To illustrate this point, coronary angiography during hospitalization was performed in $98 \%, 96 \%$ and $96 \%$ in the REV groups in ICTUS [6], FRISC-II [4] and RITA-3 [5], while it was performed in $53 \%$ of patients in ICTUS trial as compared to $7 \%$ and $16 \%$ FRISC-II and RITA-3 respectively, reflective of contemporary practice. These studies were also not powered enough to detect a long-term effect on all-cause mortality. Another proposition is that advances in medical care in general, including the use of newer drug eluting stents, newer antiplatelet agents, more adherence to guideline-directed therapy yielded further benefit for those in the SLR group closing the gap of benefit between the two groups. This includes the trend towards the use of better newer antiplatelet agents [29, 30], statins in the setting of ACS [31], the preferential use of radial approach for interventions [32], the now available second-generation drug-eluting stents [33], all of which contributed to an overall increase in favorable outcomes in management of acute cardiac ischemic events. This is evidenced by one study wherein an analysis of the GRACE cohort done on the trends between 1999 to 2006 revealed an increase in the use of beta blockers by $10 \%$, statins by $40 \%$, thienopyridines by over $50 \%$ while both angiography and percutaneous coronary intervention (PCI) rates increased by approximately $20 \%$ as well among NSTEMI and UA patients [34]. Consequently, this translated to a decrease in cardiogenic shock, heart failure, MI and death from discharge to the 6 months follow-up [34].

The findings of this meta-analysis should be interpreted with caution as the studies clumped together have high heterogeneity, specifically by the differences in follow-up. The studies with longer-term follow-up periods of 10 - 15 years like the FRISC-II [4], RITA-3 [5] and ICTUS [6] tend to have higher odds of mortality compared to the ones with shorter follow-up [12-14, 16-18, 34].

\section{Conclusions}

There was no statistical difference in all-cause mortality, MI or CABG in REV versus SLR strategy, even after analyzing trials across the Atlantic separately. Interestingly, trends of decreased all cause-mortality in REV were observed in US trials when compared to European trials. Furthermore, trends of decreased rate of $\mathrm{MI}$ and increased rate of CABG were observed in REV vs. SLR, likely driven by the results from European trials, which showed similar trends, whereas US/international trials showed comparable rates of $\mathrm{MI}$ and $\mathrm{CABG}$. Still there is significant heterogeneity between studies and these findings should be interpreted with caution. Newer studies are warranted to reflect contemporary practice.

\section{Conflict of Interest}

The authors declare that they do not have any conflict of interest.

\section{Financial Support}

The authors declare that they do not have a financial relationship with any commercial entity that has an interest in the subject of this manuscript.

\section{Author Contributions}

All authors participated to review. All authors were involved in writing and revising the article prior to submission. 


\section{References}

1. Roffi M, Patrono C, Collet JP, Mueller C, Valgimigli M, Andreotti F, Bax JJ, et al. 2015 ESC Guidelines for the management of acute coronary syndromes in patients presenting without persistent ST-segment elevation: Task Force for the Management of Acute Coronary Syndromes in Patients Presenting without Persistent ST-Segment Elevation of the European Society of Cardiology (ESC). Eur Heart J. 2016;37(3):267-315.

2. Amsterdam EA, Wenger NK, Brindis RG, Casey DE, Jr., Ganiats TG, Holmes DR, Jr., Jaffe AS, et al. 2014 AHA/ ACC guideline for the management of patients with non-ST-elevation acute coronary syndromes: executive summary: a report of the American College of Cardiology/American Heart Association Task Force on Practice Guidelines. Circulation. 2014;130(25):2354-2394.

3. Fanning JP, Nyong J, Scott IA, Aroney CN, Walters DL. Routine invasive strategies versus selective invasive strategies for unstable angina and non-ST elevation myocardial infarction in the stent era. Cochrane Database Syst Rev. 2016;5:CD004815.

4. Wallentin L, Lindhagen L, Arnstrom E, Husted S, Janzon M, Johnsen SP, Kontny F, et al. Early invasive versus non-invasive treatment in patients with non-ST-elevation acute coronary syndrome (FRISC-II): 15 year follow-up of a prospective, randomised, multicentre study. Lancet. 2016;388(10054):1903-1911.

5. Henderson RA, Jarvis C, Clayton T, Pocock SJ, Fox KA. 10 -year mortality outcome of a routine invasive strategy versus a selective invasive strategy in non-ST-segment elevation acute coronary syndrome: The British Heart Foundation RITA-3 Randomized Trial. J Am Coll Cardiol. 2015;66(5):511-520.

6. Hoedemaker NPG, Damman P, Woudstra P, Hirsch A, Windhausen F, Tijssen JGP, de Winter RJ, et al. Early Invasive Versus Selective Strategy for Non-ST-Segment Elevation Acute Coronary Syndrome: The ICTUS Trial. J Am Coll Cardiol. 2017;69(15):1883-1893.

7. McCullough PA, O'Neill WW, Graham M, Stomel RJ, Rogers F, David S, Farhat A, et al. A prospective randomized trial of triage angiography in acute coronary syndromes ineligible for thrombolytic therapy. Results of the medicine versus angiography in thrombolytic exclusion (MATE) trial. J Am Coll Cardiol. 1998;32(3):596-605.

8. Boden WE, O'Rourke RA, Crawford MH, Blaustein AS, Deedwania PC, Zoble RG, Wexler LF, et al. Outcomes in patients with acute non-Q-wave myocardial infarction randomly assigned to an invasive as compared with a conservative management strategy. Veterans Affairs NonQ-Wave Infarction Strategies in Hospital (VANQWISH) Trial Investigators. N Engl J Med. 1998;338(25):17851792.

9. Swahn E, Alfredsson J, Afzal R, Budaj A, Chrolavicius S, Fox K, Jolly S, et al. Early invasive compared with a selective invasive strategy in women with non-ST-elevation acute coronary syndromes: a substudy of the OASIS 5 trial and a meta-analysis of previous randomized trials.
Eur Heart J. 2012;33(1):51-60.

10. Michalis LK, Stroumbis CS, Pappas K, Sourla E, Niokou D, Goudevenos JA, Siogas C, et al. Treatment of refractory unstable angina in geographically isolated areas without cardiac surgery. Invasive versus conservative strategy (TRUCS study). Eur Heart J. 2000;21(23):1954-1959.

11. Thiele H, Rach J, Klein N, Pfeiffer D, Hartmann A, Hambrecht R, Sick P, et al. Optimal timing of invasive angiography in stable non-ST-elevation myocardial infarction: the Leipzig Immediate versus early and late PercutaneouS coronary Intervention triAl in NSTEMI (LIPSIANSTEMI Trial). Eur Heart J. 2012;33(16):2035-2043.

12. Montalescot G, Cayla G, Collet JP, Elhadad S, Beygui F, Le Breton H, Choussat R, et al. Immediate vs delayed intervention for acute coronary syndromes: a randomized clinical trial. JAMA. 2009;302(9):947-954.

13. van 't Hof AW, de Vries ST, Dambrink JH, Miedema K, Suryapranata H, Hoorntje JC, Gosselink AT, et al. A comparison of two invasive strategies in patients with non-ST elevation acute coronary syndromes: results of the Early or Late Intervention in unStable Angina (ELISA) pilot study. 2b/3a upstream therapy and acute coronary syndromes. Eur Heart J. 2003;24(15):1401-1405.

14. Mehta SR, Granger CB, Boden WE, Steg PG, Bassand JP, Faxon DP, Afzal R, et al. Early versus delayed invasive intervention in acute coronary syndromes. N Engl J Med. 2009;360(21):2165-2175.

15. Savonitto S, Cavallini C, Petronio AS, Murena E, Antonicelli R, Sacco A, Steffenino G, et al. Early aggressive versus initially conservative treatment in elderly patients with non-ST-segment elevation acute coronary syndrome: a randomized controlled trial. JACC Cardiovasc Interv. 2012;5(9):906-916.

16. Neumann FJ, Kastrati A, Pogatsa-Murray G, Mehilli J, Bollwein H, Bestehorn HP, Schmitt C, et al. Evaluation of prolonged antithrombotic pretreatment ("coolingoff" strategy) before intervention in patients with unstable coronary syndromes: a randomized controlled trial. JAMA. 2003;290(12):1593-1599.

17. Cannon CP, Weintraub WS, Demopoulos LA, Vicari R, Frey MJ, Lakkis N, Neumann FJ, et al. Comparison of early invasive and conservative strategies in patients with unstable coronary syndromes treated with the glycoprotein IIb/IIIa inhibitor tirofiban. N Engl J Med. 2001;344(25):1879-1887.

18. Anderson HV, Cannon CP, Stone PH, Williams DO, McCabe CH, Knatterud GL, Thompson B, et al. One-year results of the Thrombolysis in Myocardial Infarction (TIMI) IIIB clinical trial. A randomized comparison of tissue-type plasminogen activator versus placebo and early invasive versus early conservative strategies in unstable angina and non-Q wave myocardial infarction. J Am Coll Cardiol. 1995;26(7):1643-1650.

19. Riezebos RK, Ronner E, Ter Bals E, Slagboom T, Smits PC, ten Berg JM, Kiemeneij F, et al. Immediate versus deferred coronary angioplasty in non-ST-segment elevation acute coronary syndromes. Heart. 2009;95(10):807-812.

20. Spacek R, Widimsky P, Straka Z, Jiresova E, Dvorak J, Polasek R, Karel I, et al. Value of first day angiography/ 
angioplasty in evolving Non-ST segment elevation myocardial infarction: an open multicenter randomized trial. The VINO Study. Eur Heart J. 2002;23(3):230-238.

21. Reichlin T, Hochholzer W, Bassetti S, Steuer S, Stelzig C, Hartwiger S, Biedert S, et al. Early diagnosis of myocardial infarction with sensitive cardiac troponin assays. N Engl J Med. 2009;361(9):858-867.

22. Morrow DA, Cannon CP, Rifai N, Frey MJ, Vicari R, Lakkis N, Robertson DH, et al. Ability of minor elevations of troponins I and $\mathrm{T}$ to predict benefit from an early invasive strategy in patients with unstable angina and non-ST elevation myocardial infarction: results from a randomized trial. JAMA. 2001;286(19):2405-2412.

23. Diderholm E, Andren B, Frostfeldt G, Genberg M, Jernberg T, Lagerqvist B, Lindahl B, et al. ST depression in ECG at entry indicates severe coronary lesions and large benefits of an early invasive treatment strategy in unstable coronary artery disease; the FRISC II ECG substudy. The Fast Revascularisation during InStability in Coronary artery disease. Eur Heart J. 2002;23(1):41-49.

24. Van de Werf F, Gore JM, Avezum A, Gulba DC, Goodman SG, Budaj A, Brieger D, et al. Access to catheterisation facilities in patients admitted with acute coronary syndrome: multinational registry study. BMJ. 2005;330(7489):441.

25. Katritsis DG, Siontis GC, Kastrati A, van't Hof AW, Neumann FJ, Siontis KC, Ioannidis JP. Optimal timing of coronary angiography and potential intervention in non-ST-elevation acute coronary syndromes. Eur Heart J. 2011;32(1):32-40.

26. Bavry AA, Kumbhani DJ, Rassi AN, Bhatt DL, Askari AT. Benefit of early invasive therapy in acute coronary syndromes: a meta-analysis of contemporary randomized clinical trials. J Am Coll Cardiol. 2006;48(7):1319-1325.

27. Fox KA, Clayton TC, Damman P, Pocock SJ, de Winter RJ, Tijssen JG, Lagerqvist B, et al. Long-term outcome of a routine versus selective invasive strategy in patients with non-ST-segment elevation acute coronary syndrome a meta-analysis of individual patient data. J Am Coll Cardiol. 2010;55(22):2435-2445.

28. Hamm CW, Bassand JP, Agewall S, Bax J, Boersma E, Bueno H, Caso P, et al. ESC Guidelines for the manage- ment of acute coronary syndromes in patients presenting without persistent ST-segment elevation: The Task Force for the management of acute coronary syndromes (ACS) in patients presenting without persistent ST-segment elevation of the European Society of Cardiology (ESC). Eur Heart J. 2011;32(23):2999-3054.

29. Mehta SR, Yusuf S, Clopidogrel in Unstable angina to prevent Recurrent Events Study I. The Clopidogrel in Unstable angina to prevent Recurrent Events (CURE) trial programme; rationale, design and baseline characteristics including a meta-analysis of the effects of thienopyridines in vascular disease. Eur Heart J. 2000;21(24):2033-2041.

30. Wiviott SD, Braunwald E, Angiolillo DJ, Meisel S, Dalby AJ, Verheugt FW, Goodman SG, et al. Greater clinical benefit of more intensive oral antiplatelet therapy with prasugrel in patients with diabetes mellitus in the trial to assess improvement in therapeutic outcomes by optimizing platelet inhibition with prasugrelThrombolysis in Myocardial Infarction 38. Circulation. 2008;118(16):1626-1636.

31. Schwartz GG, Olsson AG, Ezekowitz MD, Ganz P, Oliver MF, Waters D, Zeiher A, et al. Effects of atorvastatin on early recurrent ischemic events in acute coronary syndromes: the MIRACL study: a randomized controlled trial. JAMA. 2001;285(13):1711-1718.

32. Romagnoli E, Biondi-Zoccai G, Sciahbasi A, Politi L, Rigattieri S, Pendenza G, Summaria F, et al. Radial versus femoral randomized investigation in ST-segment elevation acute coronary syndrome: the RIFLE-STEACS (Radial Versus Femoral Randomized Investigation in STElevation Acute Coronary Syndrome) study. J Am Coll Cardiol. 2012;60(24):2481-2489.

33. Sarno G, Lagerqvist B, Frobert O, Nilsson J, Olivecrona G, Omerovic E, Saleh N, et al. Lower risk of stent thrombosis and restenosis with unrestricted use of 'new-generation' drug-eluting stents: a report from the nationwide Swedish Coronary Angiography and Angioplasty Registry (SCAAR). Eur Heart J. 2012;33(5):606-613.

34. Fox KA, Steg PG, Eagle KA, Goodman SG, Anderson FA, Jr., Granger CB, Flather MD, et al. Decline in rates of death and heart failure in acute coronary syndromes, 1999-2006. JAMA. 2007;297(17):1892-1900. 